\title{
Light control of the respiration of exogenous glycerol in the red macroalga Grateloupia doryphora
}

\author{
R. R. ROBAINA, P. GARCÍA-JIMÉNEZ, I. BRITO AND A. LUQUE \\ Departamento de Biologia, Universidad de Las Palmas G.C., Box 550, Las Palmas G.C., Canary Islands, Spain
}

(Received 20 January 1994; accepted 18 November 1994)

\begin{abstract}
Heterotrophic activity in macroalgae has been little studied, but the red macroalga Grateloupia doryphora is known to grow in light at a higher rate in a glycerol-containing medium than in seawater. The effects of $0.1 \mathrm{M}$ exogenous glycerol in seawater (SW90-gly) on the respiration rate of $G$. doryphora and the role played by light were investigated. The algae pretreated for $2 \mathrm{~h}$ in the light and in SW90-gly evolved oxygen and fixed carbon dioxide $\left(\mathrm{H}^{14} \mathrm{CO}_{3}{ }^{-}\right)$, but also evolved radioactive ${ }^{14} \mathrm{CO}_{2}$ from $\left.{ }^{14} \mathrm{C}\right]$ glycerol. The rate of oxygen evolution was lower than that of samples in seawater, due to a high respiration rate and/or a partial inhibition of photosynthesis induced by glycerol. In contrast, the rate of inorganic carbon fixation was higher in \$W90-gly than in control samples in seawater, suggesting that non-photosynthetic patterns were operating. In darkness, after pretreatment in the light in SW90-gly, samples showed a high oxygen uptake rate just after the light was turned off. Twenty minutes of darkness were enough to decrease this high respiration rate to that of samples in seawater. The oxygen uptake observed in all experiments with glycerol was mitochondrial as it was inhibited by potassium cyanide and salicylhydroxamic acid (SHAM). Pretreatment of samples in the light in SW90-gly with the photosynthetic inhibitor DCMU did not inhibit ensuing dark respiration, thus providing evidence for a non-photosynthetic effect of the light. The highest dark respiration rate was observed after the samples were pretreated in monochromatic blue light in glycerol-containing media.
\end{abstract}

Key words: glycerol, Grateloupia doryphora, light, macroalgae, respiration.

\section{Introduction}

Inorganic carbon is the major source of carbon for most algae. Nevertheless, the ability of algae and in particular microalgae to take up and utilise organic carbon as a carbon source is well documented (Cheng \& Antia, 1970; Saunders, 1972; Bennet \& Hobbie, 1972; Neilson \& Lewin, 1974 and references therein; Ukeles \& Rose, 1976; Schwelitz et al., 1978; Nicolas et al., 1980; Kirst \& Bisson, 1983; Schwelitz et al., 1987; Markager \& SandJensen, 1990; Lewitus et al., 1991). Heterotrophic activity in macroalgae has been reported in a few scattered references (Neilson \& Lewin, 1974; Markager \& SandJensen, 1990). Recently we reported that the red macroalga Grateloupia doryphora grew at a high rate, with an increase in fresh weight $400 \%$ greater than in controls, in a glycerol-containing medium. Glycerol also promoted morphogenesis (rapid axial regeneration); it was the only effective organic carbon source for this alga (Robaina et $a l ., 1990 a, b)$. The rather high concentration of glycerol used $(0.1-0.3 \mathrm{M})$ might not be relevant to normal ecological or metabolic processes. However, an interesting point was that light was essential for algal growth at such glycerol concentrations.

To promote algal growth, any effective carbon source must provide both carbon skeletons and energy through respiratory catabolism. Respiration is not totally suppressed in light (Azcon-Bieto \& Osmond, 1983; Peltier \& Thibault, 1985; Brechignac \& Furbank, 1987; Turpin et al., 1988; Turpin, 1991), particularly when the endogenous level of carbohydrate is high and the cells are growing (Azcon-Bieto \& Osmond, 1983).

We therefore hypothesised that the necessity for light to permit accelerated growth in G. doryphora cultivated with glycerol could stem from an interaction between light, glycerol and respiration. The aim of the present work was to study the effects of exogenous glycerol and light on the respiration rate of $G$. doryphora.

\section{Materials and methods}

\section{Plant material}

Grateloupia doryphora (Montagne) Howe (voucher specimens deposited at Las Palmas herbarium (LPA, sheet no. 129) was collected on the NE coast of Gran Canaria (Canary Islands). Highly pigmented thalli with minimum contamination by algal epiphytes were selected. Two hours after collection, they were cleaned in the laboratory by washing them first with distilled water and then with autoclaved seawater. The remaining epiphytes were brushed off under a stereomicroscope.

\section{Oxygen exchange monitoring in glycerol-containing media}

Autoclaved seawater (osmolality 1.10 osmol $\mathrm{kg}^{-1}$ ) was diluted to $90 \%(\mathrm{v} / \mathrm{v})$ with double distilled water, and 
glycerol added to adjust osmolality to $1 \cdot 1 \mathrm{osmol} \mathrm{kg}{ }^{-1}$ and glycerol concentration to $0.1 \mathrm{M}$ (SW90-gly solution). This operation avoided causing osmotic stress to algal samples incubated in glycerol-containing solutions (Robaina et al., 1990a, b).

To test the effects of glycerol and light the thalli were always pretreated for $2 \mathrm{~h}$ in SW90-gly at an appropriate photon flux density (PFD, see below), then oxygen exchange was measured with an oxygen electrode (Orion) immediately after transfer of $c .1 .6 \mathrm{~g}$ fresh weight of algae to $70 \mathrm{ml}$ new solution of SW90-gly in biological oxygen demand (BOD) bottles. Oxygen uptake or evolution rates were obtained from changes in oxygen concentration when uptake or evolution was proceeding linearly $(10-20 \mathrm{~min})$.

We simulated oxygen uptake by purging oxygen from the solution with nitrogen, and oxygen release by bubbling oxygen through a solution previously purged with nitrogen. No differences were seen in SW90-gly media compared with simulation in seawater. Therefore, neither glycerol nor seawater dilution in SW90-gly appeared to influence the results obtained.

All the operations were conducted with a continuous controlled water flow at $20^{\circ} \mathrm{C}$ around the BOD bottles. When required, light (Unomat halogen lamp) was provided from the sides and the bottom of the chamber.

Epiphytic bacteria associated with $G$. doryphora thalli were removed by an ultrasound bath (Polne-Fuller et al., 1980; Robaina et al., 1990b) producing a turbid bacterial solution (c. $5 \mathrm{ml}$ per $10 \mathrm{~g}$ fresh weight algae). Oxygen uptake was less than $10 \%$ of the rates observed with algae when $5 \mathrm{ml}$ turbid bacterial solution was added to SW90gly in the same experimental conditions that we used for algae.

\section{Oxygen exchange in light}

Photosynthesis versus irradiance ( $P$ vs $I$ ) curves were obtained by recording oxygen exchange in light at PFD from 0 to $700 \mu \mathrm{mol}$ photon $\mathrm{m}^{-2} \mathrm{~s}^{-1}$. Samples were pretreated for $2 \mathrm{~h}$ in SW90-gly and light at each PFD to be tested $\left(0-700 \mu \mathrm{mol}\right.$ photon $\left.\mathrm{m}^{-2} \mathrm{~s}^{-1}\right)$. We compared them with samples in seawater. To establish whether glycerol inhibited oxygen evolution (i.e. it not only increased respiration but also inhibited photosynthesis), we first demonstrated that the short-term effect of glycerol (samples incubated for only $20 \mathrm{~min}$ in SW90gly and light or dark) on dark respiration was slight. Then we monitored the oxygen evolution rate of some samples that had not been pretreated, which were incubated over a $20 \mathrm{~min}$ period in SW90-gly at a PFD of $100 \mu$ mol photon $\mathrm{m}^{-2} \mathrm{~s}^{-1}$.

\section{Effects of light pretreatment on oxygen exchange in darkness}

We tested the effect of previous PFD on the respiration rate in ensuing dark conditions. Samples that had been kept in dim light $\left(10 \mu \mathrm{mol}\right.$ photon $\left.\mathrm{m}^{-2} \mathrm{~s}^{-1}\right)$ were pretreated at higher PFD (100 or $700 \mu \mathrm{mol}$ photon $\mathrm{m}^{-1}$ $\mathrm{s}^{-1}$ ) in SW90-gly for $2 \mathrm{~h}$. Once the light was turned off, a linear rate of oxygen uptake was obtained. We compared these results with a control kept in darkness for $2 \mathrm{~h}$.

To determine the time period over which light influenced dark oxygen uptake, the thalli were pretreated for $2 \mathrm{~h}$ at $100 \mu \mathrm{mol}$ photon $\mathrm{m}^{-2} \mathrm{~s}^{-1}$ in SW90-gly. Then, the time-course of the oxygen uptake rate after the light was turned off was followed by measuring the oxygen uptake immediately and 8, 12 and $16 \mathrm{~min}$ afterwards.

The photosynthetic inhibitor 3-(3,4-dichlorophenyl)I,I-dimethylurea (DCMU, Sigma) was used to check whether the influence of the light during the ensuing dark period was related to prior photosynthetic activity under light preincubation conditions. The samples were pretreated by incubating for $120 \mathrm{~min}$ at $100 \mu \mathrm{mol}$ photon $\mathrm{m}^{-2} \mathrm{~s}^{-1}$ in SW90-gly with $10 \mu \mathrm{M} \mathrm{DCMU}$ (a high enough concentration to inhibit completely oxygen evolution in G. doryphora; authors' unpublished data). Oxygen uptake rate was measured in subsequent darkness.

To establish the contribution of mitochondria to the oxygen uptake observed, some samples were preincubated in SW90-gly at $100 \mu \mathrm{mol}$ photon $\mathrm{m}^{-2} \mathrm{~s}^{-1}$ for $120 \mathrm{~min}$ and then the respiratory inhibitors potassium cyanide (KCN; $1 \mathrm{mM})$ and salicylhydroxamic acid (SHAM; $25 \mathrm{mM}$ ) were added and the light was turned off.

We examined the effect of light quality on dark respiration. The samples were maintained in seawater in darkness overnight. The algae were then incubated in SW90-gly and exposed to monochromatic blue $(450 \mathrm{~nm}$ peak provided by Silvania $18 \mathrm{~W}$ blue fluorescent and Rohm Plexiglas PG627 filter) and red $(640 \mathrm{~nm}$ peak provided by Silvania $18 \mathrm{~W}$ red fluorescent and Rohm Plexiglass PG502 filter). PFD was adjusted to $18 \mu \mathrm{mol}$ photon $\mathrm{m}^{-2} \mathrm{~s}^{-1}$ and the monochromatic light was supplied for $17 \mathrm{~min}$. After incubation we measured the oxygen uptake rate in ensuing darkness.

\section{Radioisotopic experiments}

To establish whether glycerol was actually being respired and not just activating respiration of endogenous substrates, we trapped carbon dioxide from algal samples ( $100 \mathrm{mg}$ fresh weight) incubated (for $2 \mathrm{~h}$ ) in light or darkness in $2 \mathrm{ml}$ seawater with $1 \mu \mathrm{Ci}(37 \mathrm{kBq})[\mathrm{U}-$ ${ }^{14} \mathrm{Clglycerol}\left(8.2 \mathrm{mCi} \mathrm{mmol}^{-1}, 0.3 \mathrm{MBq} \mathrm{mmol}^{-1}\right.$; NEN, $\mathrm{UK}$; $6 \mathrm{I} \mu \mathrm{M}$ final concentration of glycerol). Trapping involved acidification with $5 \mathrm{~N} \mathrm{HCl}$ before bubbling the air from the incubation vial to an adjacent one filled with the trapping solution Solvable (NEN, UK). The dpm values in the trapping solution were measured using a Pharmacia Wallace 1410 Liquid Scintillator Counter, using Formula 989 (NEN, UK) as scintillant. Regardless of light or dark conditions, $2 \mathrm{~h}$ of incubation with radioactive glycerol were necessary to obtain significant counts in the trapping solution.

Inorganic carbon fixation was monitored by incubating the algal samples for $20 \mathrm{~min}$ in $20 \mathrm{ml}$ seawater with $1 \mu \mathrm{Ci}$ 


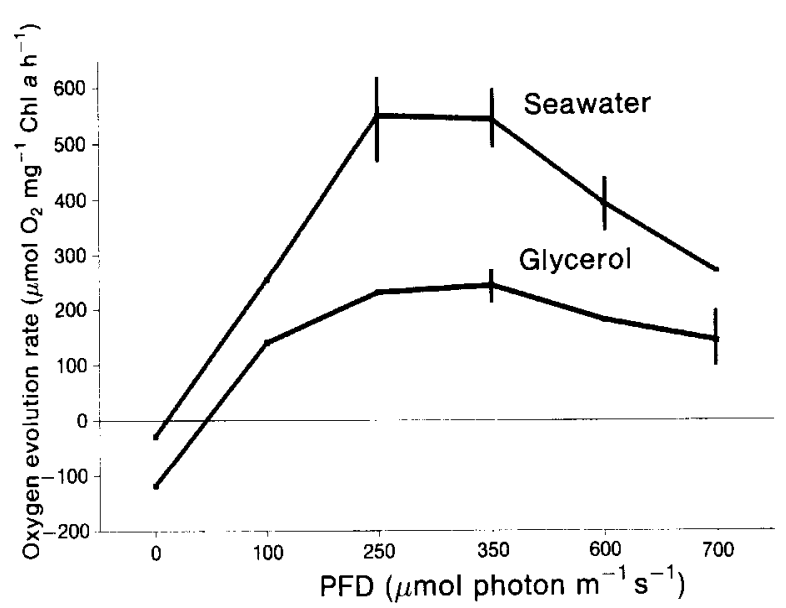

Fig. 1. Photosynthesis versus irradiance curves of samples pretreated in glycerol-containing medium (SW90-gly) and of seawater controls. Samples were pretreated for $2 \mathrm{~h}$ in SW90-gly or seawater in light of each PFD to be tested $(0-700 \mu \mathrm{mol}$ photon $\mathrm{m}^{-2} \mathrm{~s}^{-1}$ ). Data shown are the mean \pm SE of three runs with three replicates in each.

$\left[{ }^{14} \mathrm{C}\right] \mathrm{NaHCO}_{3}\left(42 \cdot 6 \mathrm{mCi} \mathrm{mmol}^{-1}, 1 \cdot 6 \mathrm{GBq} \mathrm{mmol}^{-1}\right.$; $\mathrm{NEN}$, UK). We followed standard methods for carbon isotope techniques in macroalgae (Pregnall, 1991). Carbon fixation rates in seawater after light or dark incubations in SW90-gly or in seawater were calculated by using the equation:

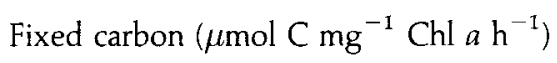

$$
=\frac{\mathrm{dpm} \text { treatment } \times \mathrm{DIC} \times 1.05}{\mathrm{dpm} \mathrm{T} \times \mathrm{mgChl} a \times \mathrm{t}}
$$

where dpm treatment is the dpm in the dimethylsulphoxide (DMSO)-soluble fraction of the sample; DIC is the carbon $(\mu \mathrm{mol})$ in $20 \mathrm{ml}$ seawater with $1.86 \mathrm{mM}$ dissolved inorganic carbon; 1.05 is a correction factor; $\mathrm{dpm} T$ is the total dpm added to incubation vial; and $t$ is the time in hours. Chl a was extracted in $90 \%$ acetone and determined spectrophotometrically using the equations of Jeffrey \& Humphrey (1975).

The carbon fixation rate of samples incubated in SW90gly and light was quantified as described above and compared with the carbon fixation rate of samples in seawater. Temperature and light were adjusted as described for the oxygen exchange experiments.

\section{Statistics}

Sigmaplot software (Sigma) was used to obtain the slopes of regression lines for oxygen concentration over time. All the experiments were performed from two to six times $(r)$ with three replicates in each $(n)$, with closely similar results. One-way ANOVA was used to compare the results obtained in the different treatments with controls in SW90-gly (Epistat statistics software). In Fig. 2 we present the results for the most representative experimental example.

\section{Results and discussion}

The effects of glycerol and light pretreatment in light

The incubation of field-collected thalli of $G$. doryphora in SW90-gly did not promote a metabolic shift from an autotrophic to a fully heterotrophic mode of nutrition in light. The $P$ vs $I$ curves (Fig. 1) show that samples pretreated in light and with glycerol for $120 \mathrm{~min}$ evolved oxygen at all light irradiances.

However, the rate of oxygen evolution in SW90-gly was $40-50 \%$ lower than that of seawater-incubated samples. This could be because: (1) the algae evolved the same quantity of oxygen (gross photosynthesis) but with a greater consumption by respiration before oxygen left the cells; (2) the algae produced a lower quantity of oxygen in gross photosynthesis; or (3) both phenomena occurred together.

The fact that $G$. doryphora grew in a glycerol-containing medium in light (Robaina et al., 1990a, b) suggested that uptake and respiration of glycerol occurred. In the present study the samples evolved radioactive carbon dioxide when incubated with [U- ${ }^{14} \mathrm{C}$ ]glycerol both in light and in darkness $(12000 \pm 3600$ and $9000 \pm 1000 \mathrm{dpm}$, respectively). The evolution of radioactive carbon dioxide from samples incubated with radioactive glycerol in the light is clear evidence for the respiration of glycerol by fieldcollected thalli. Accordingly, the lower rates of net oxygen evolution observed in the presence of glycerol may be attributed to a higher rate of oxyger uptake due to the respiration of glycerol in light.

In addition to the reduction of net oxygen uptake due to respiration of glycerol in the light, it is also possible that the alga evolved less oxygen (i.e. had a lower rate of gross photosynthesis). The incubation of the samples with glycerol in the light $\left(100 \mu \mathrm{mol}\right.$ photon $\left.\mathrm{m}^{-} 2 \mathrm{~s}^{-1}\right)$ for only $20 \mathrm{~min}$ decreased the oxygen evolution rate to $14 \%$ of those for samples in seawater $\left(270 \pm 21 \mu \mathrm{mol} \mathrm{O} \mathrm{mg}^{-1}\right.$ Chl $a \mathrm{~h}^{-1}$ ).

Glycerol affected important structural features of the photosynthetic apparatus in Pyrenomonas salina Santore (Cryptophyceae) (Lewitus et al., 1991). The use of organic carbon sources retarded greening in Euglena (Euglenophyceae) (Schwelitz et al., 1987). Wyman (1992) reported a short-term effect of glycerol in which it uncouples energy transfer between phycoerythrin and other biliproteins of the Synechococcus (Cyanobacteria) phycobilisome. It is possible that glycerol reduced photosynthetic performance in $G$. doryphora also; this requires further investigation.

It should be noted that the algae recover their photosynthetic activity from $14 \%$ of the control value in the short-term incubation (20 $\mathrm{min}$ ) to $40-50 \%$ in samples incubated for longer (120 min; Fig. I).

Table 1 shows the carbon fixation rates in light and darkness for samples preincubated with glycerol in light. The highest level of carbon fixation was obtained in light after preincubation with glycerol in light. It was significantly higher $(0.01<p \leq 0.05)$ than the highest rate of 
Table 1. Carbon fixation rate $\left(\mu \mathrm{mol} \mathrm{C} \mathrm{mg}{ }^{-1} \mathrm{Chl} a \mathrm{~h}^{-1}\right)$ in light and dark of samples pretreated for $2 \mathrm{~h}$ in light (at $100 \mu \mathrm{mol}$ photon $\mathrm{m}^{-2} \mathrm{~s}^{-1}$ ), in SW90-gly or seawater. Controls were samples kept in darkness

\begin{tabular}{lccr}
\hline \hline Medium & Light & Dark & Control \\
\hline SW90-gly & $1017 \pm 125^{* * *}$ & $37 \cdot 5 \pm 6 \cdot 7^{* *}$ & $72 \cdot 5 \pm 5 \cdot 8^{\text {n.s. }}$ \\
Seawater & $684 \pm 75^{* * *}$ & $36 \cdot 6 \pm 6 \cdot 0^{* *}$ & $100 \cdot 8 \pm 6 \cdot 7^{* *}$ \\
\hline
\end{tabular}

Data shown are the means $\pm S E$ from three experiments with three replicates in each, statistically compared with controls in SW90-gly. n.s., non-significant; ${ }^{* *} 0.001<p \leq 0.01 ;{ }^{* * *} p \leq 0.001$

oxygen evolution (i.e. that for the non-glycerol-treated controls) seen in Fig. 1, which is in contrast to the rather low oxygen evolution rate discussed above.

The pathways of non-photosynthetic carbon fixation (i.e. anaplerotic carboxylating pathways) may contribute more in glycerol-incubated samples than in samples coming from seawater since these samples respired at a higher rate. Anaplerotic fixation of inorganic carbon normally joins respiratory metabolism at the PEP level and leads to the accumulation of (inter alia) organic acids. We simply checked the $\mathrm{pH}$ of the homogenates from glycerol-incubated samples. The $\mathrm{pH}$ went down to a value of $2.75-3.00$ in samples incubated with glycerol in light, whilst it was around $\mathrm{pH} 7.0$ in those incubated in seawater. We have observed (unpublished) that samples exposed to glycerol and light accumulated more radioactivity from $\mathrm{H}^{14} \mathrm{CO}_{3}{ }^{-}$in the anionic fraction than did samples in seawater, in which radioactivity accumulated preferentially in the neutral fraction.

While the observations described above provide evidence for a higher anaplerotic fixation of carbon with glycerol in light, the results of light-to-dark transition (Table I) unexpectedly indicated that any such anaplerotic fixation in glycerol did not continue from the light period to the ensuing dark as might have been expected.

These data suggest that incubation of $G$. doryphora in light with glycerol in the medium led to the activation of a non-photosynthetic pattern of carbon fixation, which results in higher ${ }^{14} \mathrm{C}$-carbon fixation rates and lower net oxygen evolution rates. Determining whether this relates to respiratory metabolism, to anaplerotic pathways or to specific pathways derived from glycerol metabolism requires precise identification of the compounds accumulated after incubation in glycerol.

\section{The effect of glycerol and light pretreatment in darkness}

Photosynthesis and respiration have opposing effect on net oxygen exchange, thus complicating measurements in the light. More valuable and readily interpretable results were expected to be obtained in darkness following pretreatment in glycerol and light.

The results in Table 2 confirm that thalli collected from
Table 2. Oxygen uptake rate $\left(\mu \mathrm{mol} \mathrm{O} \mathrm{mg}^{-1} \mathrm{Chl} \mathrm{a} \mathrm{h}^{-1}\right)$ in the dark of samples after $2 \mathrm{~h}$ pretreatment in SW90-gly or seawater in the light (700 or $100 \mu \mathrm{mol}$ photon $\mathrm{m}^{-2} \mathrm{~s}^{-1}$ )

\begin{tabular}{|c|c|c|c|}
\hline \multirow[b]{2}{*}{ Medium } & \multicolumn{2}{|c|}{ Pretreatment ( $\mu$ mol photon $\left.\mathrm{m}^{-2} \mathrm{~s}^{-1}\right)$} & \multirow[b]{2}{*}{ Dark } \\
\hline & 700 & 100 & \\
\hline SW90-gly & $176 \pm 9^{* *}$ & $147 \pm 9^{*}$ & $119 \pm 10^{\text {n.s }}$ \\
\hline Seawater & $98 \pm 2^{*}$ & $100 \pm 2^{*}$ & $59 \pm 9^{* *}$ \\
\hline
\end{tabular}

Data are the means $\pm S E$ of six experiments with three replicates in each, statistically compared with samples pretreated for $2 \mathrm{~h}$ in SW90-gly in darkness.

n.s., non-significant; ${ }^{*} 0.01<p \leq 0.05 ;{ }^{* *} 0.001<p \leq 0.01$.

their natural habitat were able to respire at a high rate after $2 \mathrm{~h}$ of pretreatment in glycerol. The fact that they evolved ${ }^{14} \mathrm{CO}_{2}$ from $\left[{ }^{14} \mathrm{C}\right]$ glycerol, as discussed above, indicates that they respired exogenous glycerol. The presence of light in the pretreatment also played an important role. The respiration rate in the dark increased significantly with increasing PFD of the pretreatment in the preceding light period (Table 2 ).

Light plays a central role in the uptake and metabolism of organic carbon in several algae (Cheng \& Antia, 1970; Bennet \& Hobbie, 1972; Neilson \& Lewin 1974; Andersag \& Pirson, 1976; Nicolas et al., 1980; Kirst \& Bisson, 1983; Markager \& Sand-Jensen, 1990). G. doryphora did not grow on glycerol in the dark (Robaina et al. 1990b) even though glycerol was respired in the darkness by fieldcollected thalli (Table 2). The rate of respiration of exogenous glycerol is apparently not adequate to permit growth. We suggest that the combination of light-dependent carbon metabolism (and energy transduction?) with the presence of glycerol (carbon and energy) is necessary to promote growth.

Following the occurrence of this light effect on dark respiration (Fig. 2), it was observed that in contrast to the normal post-illumination respiratory burst in seawater samples, the time-course in glycerol medium showed a decrease in dark respiration within $20 \mathrm{~min}$ of the light being turned off. This is probably due to the shift from light-activated respiration in glycerol medium to normal dark respiration. A sharp increase in dark respiration within 2 min of the end of the light period is less plausible than a continuation of a higher rate in the light, although it is possible.

The inhibitors KCN and SHAM have been used to demonstrate that oxygen uptake by algae results from mitochondrial respiratory activity (Peltier \& Thibault, 1985; Brechignac \& Furbank, 1987). Weger et al. (1989) inhibited photorespiratory (including Mehler reaction) oxygen uptake with an incubation in DCMU in mass spectrometry experiments. Our results with inhibitors (Table 3) showed that only KCN and SHAM inhibited the oxygen uptake, meaning that respiratory oxygen uptake in glycerol medium in light or dark reported in 


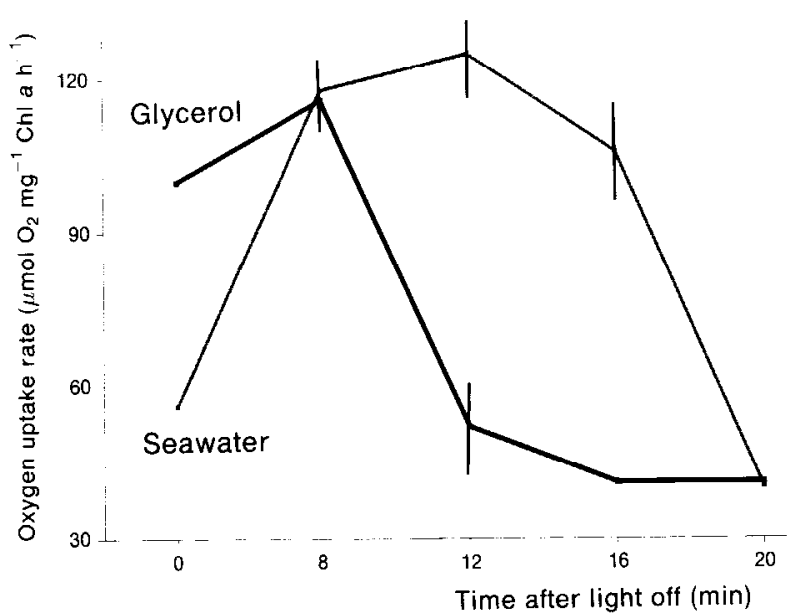

Fig. 2. Time course of oxygen uptake rate in darkness $0,8,12$, 16 and $20 \mathrm{~min}$ after the pretreatment of samples for $2 \mathrm{~h}$ in SWgly in light $\left(100 \mu \mathrm{mol}\right.$ photon $\left.\mathrm{m}^{-2} \mathrm{~s}^{-1}\right)$. Data shown are the most representative of six runs with three replicates in each.

this work is mitochondrial. It should be noted that SHAM must be added to inhibit respiration (less than $20 \%$ inhibition with $\mathrm{KCN}$ alone), supporting the existence of the alternative pathway of respiration in $G$. doryphora.

It is likely that in $G$. doryphora, as in other organisms, glycerol is phosphorylated to glycerol-3-phosphate (De Koning et al., 1987). If metabolism of glycerol or glycerolderived organic carbon sources (i.e. endogenous pathways) starts with phosphorylation in G. doryphora, extra ATP would be required to metabolise the net influx of glycerol. This extra ATP could come initially from photosynthetic thylakoid reactions; thus the light would be important to provide ATP in G. doryphora incubated in glycerol. Glycerol reduced (inhibited) photosynthesis (Fig. 1), while respiration continued at the highest rate at PFD levels which were photoinhibitory for oxygen evolution $\left(700 \mu\right.$ mol photon $\mathrm{m}^{-2} \mathrm{~s}^{-1}$; Fig. 1, Table 2) and DCMU addition in the light period did not inhibit dark respiration (Table 3). The light-activated respiration of glycerol does not seem to be dependent on 'photosynthetic ATP' supply to the metabolism of glycerol.

Table 3. Oxygen uptake rate $\left(\mu \mathrm{mol} \mathrm{O}_{2} \mathrm{mg}^{-1} \mathrm{Chl} \mathrm{ah^{-1 }}\right)$ in the dark of samples after pretreatment for $2 \mathrm{~h}$ in SW90-gly or seawater in the light $\left(100 \mu \mathrm{mol}\right.$ photon $\left.\mathrm{m}^{-2} \mathrm{~s}^{-1}\right)$ with the inhibitors KCN (1 mM) + SHAM $(25 \mathrm{mM})$ or DCMU (10 $\mu \mathrm{M})$. Controls were samples without inhibitors

\begin{tabular}{lccc}
\hline \hline Medium & KCN + SHAM & DCMU & Control \\
\hline SW90-gly & $18 \pm 5^{* * *}$ & $96 \pm 1^{\text {n.s. }}$ & $98 \pm 2^{\text {n.s. }}$ \\
Seawater & $19 \pm 9^{* * *}$ & $61 \pm 1^{* * *}$ & $56 \pm 1^{* * *}$ \\
\hline \hline
\end{tabular}

Data shown are the means \pm SE of six experiments with three replicates in each, statistically compared with controls in SW90-gly. KCN and SHAM were added just before the light was turned off. n.s., non-significant; ${ }^{* * *} p \leq 0.001$

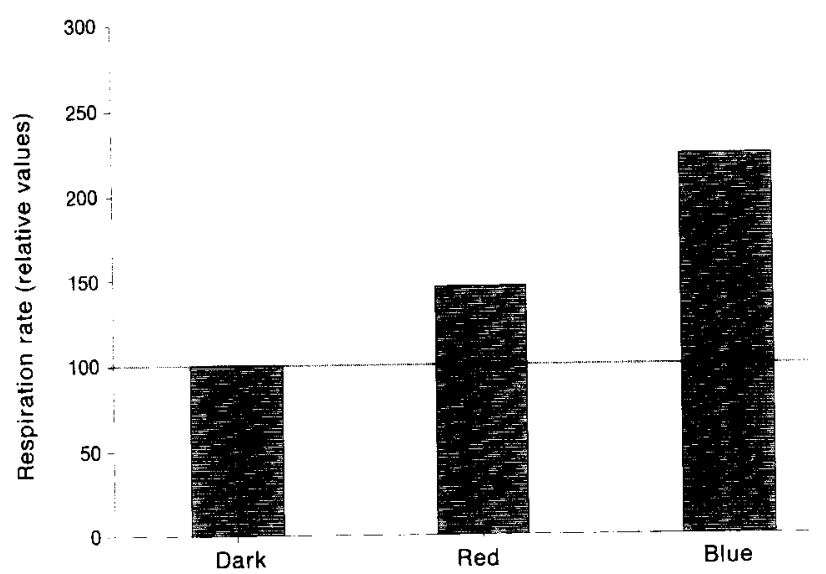

Fig. 3. Effect of pretreatment with glycerol in monochromatic blue ( $450 \mathrm{~nm}$ peak) and red $(640 \mathrm{~nm}$ pcak) light on subsequent dark respiration. Photon flux density was adjusted to $18 \mu \mathrm{mol}$ photon $\mathrm{m}^{-2} \mathrm{~s}^{-1}$ for $17 \mathrm{~min}$. Results are expressed as a percentage of respiration in samples kept in darkness and represent the means of three runs with three replicates in each (100\% was $\left.58.3 \pm 6 \mu \mathrm{mol} \mathrm{O} \mathrm{mg}^{-1} \mathrm{Chl} \mathrm{a} \mathrm{h}^{-1}\right)$.

In searching for a more precise role of light in the respiration of glycerol, the results in Fig. 3 clearly demonstrated differential effects of red and blue light. Samples under blue light increased respiration to $225 \%$ of values of control unexposed samples (dark rate, $100 \%$ in Fig. 3). This agrees with reports of blue-light activation of respiration (Andersag \& Pirson, 1976; Kowallik \& Schätzle, 1980; Kowallik, 1982; Ruyters, 1988). It also opens up an interesting field of research since $G$. doryphora incubated with glycerol provides a system for studying the effects of light on dark respiration under conditions in which respiratory pathways are enhanced.

In conclusion, glycerol inhibited oxygen evolution and enhanced mitochondrial oxygen uptake of field-collected thalli of $G$. doryphora. The evolution of ${ }^{14} \mathrm{CO}_{2}$ from $[\mathrm{U}$ ${ }^{14}$ Clglycerol-incubated algae indicates that glycerol was actually respired. Light plays a central role by activating glycerol respiration, with evidence of the effects being related to the light quality (the greatest enhancement being by blue light).

\section{Acknowledgements}

This work was supported by the Government of the Canary Islands (grant 122/03.08.1990). The fellowships of the University of Las Palmas G.C. to P.G-J. and of the Fundacion Universitaria de Las Palmas to I.B. are also acknowledged. We thank Jose Antonio Martín for his technical assistance in experiments with radioisotopes.

\section{References}

ANDERSAG, R. \& PirSON; A. (1976). Utilization of glucose by cultures of Chlorella in red and blue light. Biochem. Physiol. Pflanzen., 169: 71-85 AzCON-Bieto, J. \& OsMond, B. (1983). Relationship between photosynthesis and respiration: the effect of carbohydrate status on the rate of $\mathrm{CO}_{2}$ 
production by respiration in darkened and illuminated wheat leaves. Plant Physiol., 71: 574-581.

BENNET; M.E. \& HOBBIE, J.E. (1972). The uptake of glucose by Chlamydomonas sp. J. Phycol, 8: 392-398.

BRECHIGNAC, F. \& Furbank, K.T. (1987). On the nature of the oxygen uptake in the light by Chondrus crispus: effects of inhibitors, temperature and light intensity. Phot. Res., 11: 45-59.

CHENG, J.Y. \& ANTIA, N.J. (1970). Enhancement by glycerol of phototrophic growth of marine planktonic algae and its significance to the ecology of glycerol pollution. J. Fish. Res. Bd. Canada, 27: 335-346.

De Koning, W., Harder, W. \& DijkHUIzen, L. (1987). Glycerol metabolism in the methylotrophic yeast Hansenula polymorpha: phosphorylation as the initial step. Arch. Microbiol.. 148: 314-320.

JEFFREY, S.W. \& HUMPHREY, G.W. (1975). New spectrophotometric equations for determining chlorophylls $a, b, c$ and $c_{2}$ in higher plants, algae and natural phytoplankton. Biochem. Physiol. Pflanz, 46: 191-194.

KiRST, G.O.\& BISSON, M.A. (1983). Sugar uptake in a euryhaline charophyte, Lamprothamnium papulosum. Z. Pflanzenphysiol., 111: 105-I I4.

Kowallik, W. (1982). Blue light effects on respiration. Annu. Rev. Plant Physiol., 33: 51-72.

KowALLIK, W. \& SCHÄTZLE, S. (1980). Enhancement of carbohydrate degradation by blue light. In The Blue Light Syndrome (Senger, $\mathrm{H}$., editor) 344-360. Springer-Verlag, Berlin.

Lewitus, A.J., CARON, D.A. \& Miller, K.R. (1991). Effects of light and glycerol on the organization of the photosynthetic apparatus in the facultative heterotroph Pyrenomonas salina (Cryptophyceae). J. Phycol., 27: $578-587$

Markager, S. \& SAND-JENSEN, K. (I990). Heterotrophic growth of Ulva lactuca (Chlorophyceae). J. Phycol, 26: 670-673.

NeilSON, A.H. \& LEWTN, R.A. (1974). The uptake and utilization of organic carbon by algae: an essay in comparative biochemistry. Phycologia, 13: 227-264.

Nicolas, P., Freysinet, G. \& Nigon, V. (1980). Effect of light on glucose utilization by Euglena gracilis. Plant Physiol., 65: 631-634

Peltier, G. \& Thibalt, P. (1985). $\mathrm{O}_{2}$ uptake in the light in Chlamydomonas. Plant Physiol, 79: 225-230
Polne-Fuller, M., Gibor, A. \& Neushul, M. (1980). The use of ultrasound for the removal of macroalgal epiphytes. Bot. Mar. 23: 731-734.

Pregnall, A.M. (1991). Photosynthesis/translocation: aquatic. In (Coleman C., Fry, B., editors), 53-75. Carbon Isotope Techniques. Academic Press, San Diego.

Robaina, R.R., Garcia-Reina, G. \& LuQue, A. (1990a). The effects of the physical characteristics of the culture medium on the development of red seaweeds in tissue culture. Hydrobiologia, 204/205: 137-142.

Robaina, R.R., García, P., Garcia-Reina, G. \& Luque, A. (1990b). Morphogenetic effect of glycerol on tissue cultures of the red seaweed Grateloupia doryphora. J. appl. Phycol. 2: 137-143.

RUYTERS, G. (1988). Light stimulated respiration in the green alga Dunaliella tertiolecta: involvement of the ultraviolet/blue light photoreceptor(s) and phytochrome. Planta, 174: 422-425.

SAUNDERS, G.W. (1972). Potential heterotrophy in a natural population of Oscillatoria agardhii var. isothrix Skuja. Limnol. Oceanogr., 17: 704-711.

Schwelitz, F.D., Cisneros, P.L. \& JAcielo, J.A. (1978). The effect of glucose of the biochemical and structural characteristics of developing Euglena chloroplasts. J. Protozool, 25: 398-403.

SChWelttz, F.D., Cisneros, P.L., Jagielo, J.A., Comer, J.L. \& Butterfield, K.A. (1987). The relationship of fixed carbon and nitrogen sources to the greening process in Euglena gracilis strain Z. J. Protozool, 25: 257-261.

TURPIN, D.H. (1991). Effects of inorganic $\mathrm{N}$ availability on algal photosynthesis and carbon metabolism. J. Phycol, 27: 14-20.

TuRPIN, D.H., ElRIFi, 1.R., BIRCH, D.G., WEGER, H.G. \& HOLWES, J.J. (1988). Interaction between photosynthesis, respiration and nitrogen assimilation in algae. Can. J. Bot., 66: 2083-2097.

UKELES, R. \& ROSE, W.E. (1976). Observation on organic carbon utilization by photosynthetic marine microalgae. Mar. Biol, 37: 11-28.

WeGER, H.G., HeRZIG, R., FALKOWSK, P.G. \& TURPIN, D.H. (1989). Respiratory losses in the light in a marine diatom: measurements by short term mass spectrometry. Limnol. Ooceanogr. 34: 1153-1161.

WYMAN, M. (1992). An in vivo method for the estimation of phycoerythrin concentrations in marine cyanobacteria (Synechococcus sp.). Limnol. Oceanogr., 37: 1300-1306. 